\title{
Methylprednisolone for the Treatment of Patients with Acute Spinal Cord Injuries: A Propensity Score-Matched Cohort Study from a Canadian Multi-Center Spinal Cord Injury Registry
}

\author{
Nathan Evaniew, Vanessa K. Noonan,,3 Nader Fallah,,3 Brian K. Kwon,, ${ }^{3}$ Carly S. Rivers, ${ }^{2}$ Henry Ahn, ${ }^{4,5}$ \\ Christopher S. Bailey, ${ }^{6}$ Sean D. Christie, ${ }^{7}$ Daryl R. Fourney, ${ }^{8}$ R. John Hurlbert, ${ }^{9}$ A.G. Linassi, ${ }^{10}$ \\ Michael G. Fehlings, ${ }^{5,11}$ Marcel F. Dvorak, ${ }^{3}$ and The RHSCIR Network
}

\begin{abstract}
In prior analyses of the effectiveness of methylprednisolone for the treatment of patients with acute traumatic spinal cord injuries (TSCIs), the prognostic importance of patients' neurological levels of injury and their baseline severity of impairment has not been considered. Our objective was to determine whether methylprednisolone improved motor recovery among participants in the Rick Hansen Spinal Cord Injury Registry (RHSCIR).

We identified RHSCIR participants who received methylprednisolone according to the Second National Spinal Cord Injury Study (NASCIS-II) protocol and used propensity score matching to account for age, sex, time of neurological exam, varying neurological level of injury, and baseline severity of neurological impairment. We compared changes in total, upper extremity, and lower extremity motor scores using the Wilcoxon signed-rank test and performed sensitivity analyses using negative binomial regression.

Forty-six patients received methylprednisolone and 1555 received no steroid treatment. There were no significant differences between matched participants for each of total (13.7 vs. 14.1 , respectively; $p=0.43$ ), upper extremity (7.3 vs. 6.4; $p=0.38)$, and lower extremity ( 6.5 vs. $7.7 ; p=0.40)$ motor recovery. This result was confirmed using a multivariate model and, as predicted, only cervical $(\mathrm{C} 1-\mathrm{T} 1)$ rather than thoracolumbar (T2-L3) injury levels $(p<0.01)$ and reduced baseline injury severity (American Spinal Injury Association [ASIA] Impairment Scale grades; $p<0.01$ ) were associated with greater motor score recovery. There was no in-hospital mortality in either group; however, the NASCIS-II methylprednisolone group had a significantly higher rate of total complications $(61 \%$ vs. $36 \% ; p=0.02)$

NASCIS-II methylprednisolone did not improve motor score recovery in RHSCIR patients with acute TSCIs in either the cervical or thoracic spine when the influence of anatomical level and severity of injury were included in the analysis. There was a significantly higher rate of total complications in the NASCIS-II methylprednisolone group. These findings support guideline recommendations against routine administration of methylprednisolone in acute TSCI.
\end{abstract}

Key words: methylprednisolone; motor score; neurological recovery; propensity scored-matched; spinal cord injury

${ }^{1}$ Division of Orthopaedics, McMaster University, Hamilton, Ontario, Canada.

${ }^{2}$ Rick Hansen Institute, ${ }^{3}$ University of British Columbia, Vancouver, Canada.

${ }^{4}$ St. Michael's Hospital, Toronto, Ontario, Canada.

${ }^{5}$ University of Toronto Spine Program, ${ }^{11}$ Division of Neurosurgery, University of Toronto, Ontario, Canada.

${ }^{6}$ Division of Orthopaedic Surgery, Western University; London Health Services Centre, London, Ontario, Canada.

${ }^{7}$ Division of Neurosurgery-Halifax Infirmary, Dalhousie University, Halifax, Nova Scotia, Canada.

${ }^{8}$ Department of Surgery, ${ }^{10}$ Department of Physical Medicine and Rehabilitation, University of Saskatchewan, Saskatoon, Saskatchewan, Canada

${ }^{9}$ University of Calgary Spine Program, Calgary, Alberta, Canada.

(c) Nathan Evaniew, Vanessa K. Noonan, Nader Fallah, Brian K. Kwon, Carly S. Rivers, Henry Ahn, Christopher S. Bailey, Sean D. Christie, Daryl R. Fourney, R. John Hurlbert, A. G. Linassi, Michael G. Fehlings, Marcel F. Dvorak, and The RHSCIR Network 2015; Published by Mary Ann Liebert, Inc. This Open Access article is distributed under the terms of the Creative Commons Attribution Noncommercial License (http://creativecommons.org/ licenses/by-nc/4.0/) which permits any noncommercial use, distribution, and reproduction in any medium, provided the original author(s) and the source are credited. 


\section{Introduction}

$\mathbf{T}$ RAUMATIC SPINAL CORD INJURIES (TSCIs) affect up to 500,000 people worldwide each year, and their high morbidity is associated with substantial individual and societal burden and socioeconomic impact. ${ }^{1,2}$ Patients with TSCIs often experience devastating neurological impairments, and they frequently require complex long-term multidisciplinary care. ${ }^{3,4}$ Total health care costs related to TSCIs exceed $\$ 10$ billion annually in the United States alone, and lifetime per person direct and indirect costs can exceed $\$ 3$ million. ${ }^{5,6}$ TSCIs most commonly affect young males and result from road traffic accidents, but recent reports also highlight their increasing incidence in older adults as a result of low-energy falls. ${ }^{2,7-9}$

The identification of novel interventions to reduce the morbidity of TSCIs is an urgent ongoing research priority. ${ }^{3,10}$ Methylprednisolone is a corticosteroid that was proposed to inhibit the inflammatory cascades contributing to secondary spinal cord damage after TSCIs, but its clinical utility remains controversial. ${ }^{11,12}$ Considerable debate has centered on the validity of results from the landmark Second National Spinal Cord Injury Study (NASCIS-II), which was published in $1990 .{ }^{11,13,14}$ In NASCIS-II, 487 patients with acute TSCIs were randomized to an initial bolus of $30 \mathrm{mg} / \mathrm{kg}$ of methylprednisolone followed by an infusion of $5.4 \mathrm{mg} / \mathrm{kg}$ per $\mathrm{h}$ for $23 \mathrm{~h}$ versus either naloxone or placebo.

The primary analysis among the 487 patients enrolled within $12 \mathrm{~h}$ in NASCIS-II failed to demonstrate a significant neurological benefit in the 162 patients randomized to methylprednisolone. However, a secondary analysis of 65 of these patients who received methylprednisolone within $8 \mathrm{~h}$ of injury suggested that this subgroup experienced improved neurological recovery at 6 months. ${ }^{13,15}$ Critics of NASCIS-II highlight the limited credibility of subgroup testing, the potential importance of losses to follow-up, the small magnitude of observed treatment effects, and the arbitrary nature of an 8-h threshold. ${ }^{14,16-19}$ Advocates discuss a lack of otherwise high-quality evidence and cite indirect support elsewhere in the literature. ${ }^{15,20}$

The use of methylprednisolone has decreased dramatically in many centers, but some clinicians still report a belief in its efficacy or concerns about medical-legal pressure. ${ }^{21-25}$ Potential harms include increased risks for respiratory, urinary tract, and wound infections, hyperglycemia, gastrointestinal hemorrhage, steroidinduced myopathy, and all-cause mortality. ${ }^{17,26,27}$ Early critical reviews of the NASCIS studies recommended that methylprednisolone administration not be considered a "standard of care" for acute TSCI, but rather, a treatment option. More recently, the 2013 "Guidelines for the Management of Acute Cervical Spine and Spinal Cord Injuries" recommended against the routine administration of methylprednisolone for the treatment of acute TSCIs. ${ }^{28-30}$

Recent evidence from the Rick Hansen Spinal Cord Injury Registry (RHSCIR) suggests that the prognostic importance of patients' neurological level of injury in combination with the baseline severity of their neurological impairments may have been previously overlooked. ${ }^{3}$ Controlling for the joint distribution of these two variables in TSCI research might increase the likelihood of detecting true treatment effects while simultaneously avoiding spurious or misleading results. ${ }^{31}$ In this study, our primary objective was to determine whether the NASCIS-II regimen of methylprednisolone started within $8 \mathrm{~h}$ of injury improved motor recovery in comparison with no steroid treatment among RHSCIR patients with acute TSCIs. Our secondary objectives were to consider the effect of patients' neurological level of injury and the baseline severity of their neurological impairments on motor recovery, and to compare rates of complications between groups.

\section{Methods}

\section{Study design}

We performed a propensity score-matched cohort study using patient data that were prospectively collected in RHSCIR. RHSCIR is an ongoing multi-center observational study of patients with acute TSCIs who are admitted to major trauma centers and accompanying rehabilitation centers in Canada. ${ }^{32}$ There are currently 31 participating study sites in the RHSCIR network, which are located across 16 cities from 9 out of 10 Canadian provinces. This article's primary objective was specified a priori during the development of RHSCIR, along with several other research objectives. $^{32}$ Each participating site obtained local Research Ethics Board or Institutional Review Board approval prior to enrolling patients and collecting data.

\section{Participants}

Patients were eligible for this study if they were 18 years of age or older and they presented to a participating site following an acute TSCI. Patients with non-traumatic etiologies of SCI such as infection, neoplasm, iatrogenic, or acute vascular causes were ineligible, but no exclusions were made on the basis of age, sex, medical co-morbidities, associated injuries, or planned treatment. According to the RHSCIR protocol, approximately 265 data elements were collected during participants' pre-hospital, acute, and rehabilitation phases of care. Further descriptions of the RHSCIR data elements, procedures, governance structure, and patient privacy and confidentiality framework are available elsewhere. .,32,33 $^{2}$

We used the RHSCIR database to identify all patients from May 2004 to March 2014 who received either the NASCIS-II regimen of methylprednisolone started within $8 \mathrm{~h}$ of their acute injury or no steroid treatment. Patients who received regimens of methylprednisolone other than NASCIS-II, patients who received steroids other than methylprednisolone, and patients whose steroid status was indeterminate were excluded. Patients who received the NASCIS-II regimen followed by an additional $24 \mathrm{~h}$ of methylprednisolone were included. ${ }^{15}$

The indications for NASCIS-II methylprednisolone were not standardized across the participating sites, and patients could have received NASCIS-II methylprednisolone at RHSCIR acute care sites or at non-participating community hospitals prior to being transferred to an RHSCIR acute care site.

\section{Data sources}

Motor function scores were measured by trained physicians, nurse practitioners, or physiotherapists according to the International Standards for Neurological Classification of Spinal Cord Injury (ISNCSCI). ${ }^{34}$ ISNCSCI total motor scores (TMS) can range from 0 (absent motor function) to 100 (intact motor function) and comprise component upper extremity motor scores (UEMS; range $0-50$ ), and lower extremity motor scores (LEMS; range $0-50$ ). We considered patients' baseline motor scores to be those obtained on their admission to acute care and we considered patients' final motor scores to be those obtained at the time of their discharge to the community from acute care or inpatient rehabilitation. ${ }^{31}$ Each ISNCSCI record was processed through a customized electronic algorithm that maintained consistency and high quality. ${ }^{32}$

We also retrieved the following variables from the RHSCIR database for each patient: age, sex, Body Mass Index, Glasgow Coma Scale and Injury Severity Score at admission, injury mechanism, Charlson Comorbidity Index, ${ }^{35}$ whether or not patients underwent surgery, and RHSCIR study site. These data elements were collected by trained research personnel and entered into 
standardized local RHSCIR databases before being exported to the RHSCIR national office for centralized quality checks. ${ }^{32}$ Missing or ambiguous data were reconciled with local research coordinators, hospital health records, and medical chart abstraction whenever possible.

We collected rates of in-hospital mortality, urinary tract infections (UTIs), pneumonias, decubitus ulcers, deep vein thrombosis or pulmonary embolism, surgical site infections, and sepsis using International Classification of Diseases, 10th Revision (ICD-10) codes from the Canadian Institute for Health Information's Discharge Abstract Database. ${ }^{36}$

\section{Statistical analysis}

We used 1:1 propensity score matching based on logistic regression to match patients who received NASCIS-II methylprednisolone with controls who received no steroid treatment. To control for potential confounding, we matched according to varying neurological level of injury (cervical: C1-T1, or thoracic: T2-L3) and baseline severity of neurological impairments (ISNCSCI ASIA Impairment Scale A, B, C, or D), as well as age, sex, and time from injury to first neurological examination $(<72 \mathrm{~h}, 72 \mathrm{~h}$ to one week, greater than one week, or unknown). ${ }^{3,37-39}$

Jitter plots and propensity histograms were used to verify the distribution of propensity scores in each group. Sensitivity analysis were performed to control for any residual imbalance by (i) comparing the matched groups while adjusting for the matched variables using negative binomial regression; and (ii) comparing the NASCIS-II methylprednisolone group against the full cohort of unmatched potential controls while adjusting for the same variables and RHSCIR site using negative binomial regression. ${ }^{40}$ Goodness of fit was confirmed using the Akaike information criterion and the Bayesian information criterion.

Discrete variables are reported as counts or proportions, normally distributed continuous variables as means with standard deviations (SD), and skewed continuous variables as medians with interquartile ranges (IQR). We used parametric tests for data with normal distributions and non-parametric tests for data without normal distributions. ${ }^{3,31}$ We compared unmatched groups with the independent samples $t$ test using Levene's test to assess the equality of variance or the Mann-Whitney U test, and matched groups with the paired $t$ test or the Wilcoxon signed-rank test. We used Pearson's $\chi^{2}$ or Fisher's exact test for categorical data depending upon the number of the sample in each cell. Direct correlations were evaluated using Pearson's correlation coefficient.

Participants with missing data were excluded from each analysis and imputations were not performed. ${ }^{18,41}$ Extreme outliers were removed from each group when comparing lengths of stay. All tests of significance were two-tailed and $p$ values of less than 0.05 were considered significant. All analyses were performed using R 3.1 (CRAN: the Comprehensive R Archive Network at http://cran.rproject.org/), Excel 2011 (Microsoft Corp., Redmond, WA), and IBM SPSS Version 22, 2012 (SPSS Inc., Chicago IL).

\section{Results}

\section{Participants}

There were 2009 patients with acute TSCIs who consented to RHSCIR enrollment and were discharged to the community from acute care or inpatient rehabilitation (Fig. 1). Of these, we excluded 318 because their steroid administration status was indeterminate,

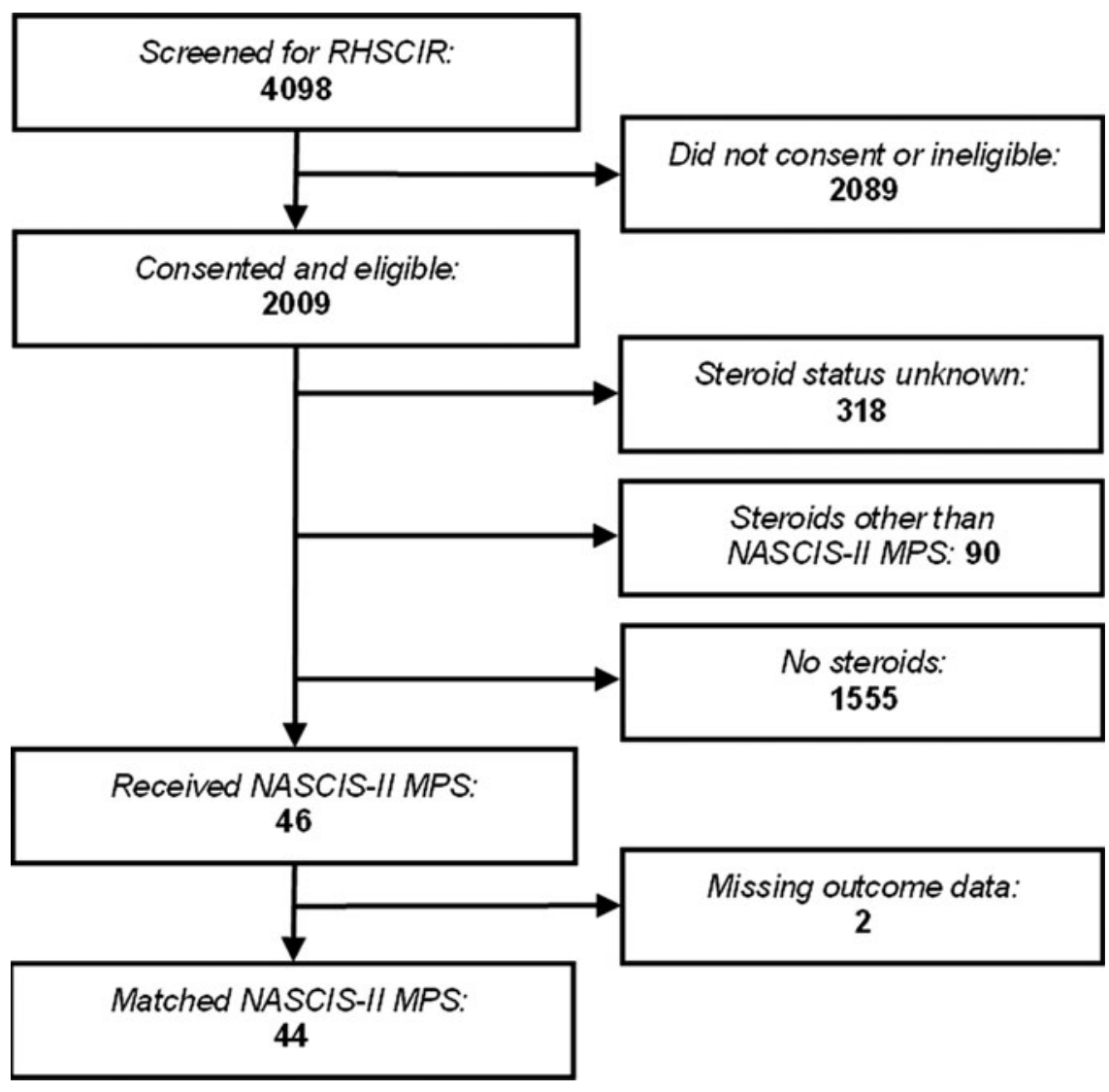

FIG. 1. Flow of participants in the RHSCIR and selection of patients for propensity score matching. MPS, methylprednisolone; RHSCIR, Rick Hansen Spinal Cord Injury Registry. 
72 because they received dexamethasone, 5 because they received non-NASCIS-II methylprednisolone, and 14 because they received steroid regimens that were not further specified. In total, 46 consecutive patients were included who received the NASCIS-II regimen of methylprednisolone within $8 \mathrm{~h}$ of their acute injury, 5 of whom received the NASCIS-II regimen followed by an additional $24 \mathrm{~h}$ of methylprednisolone. There were 1555 included patients who received no steroid treatment.

Of the 46 patients who received NASCIS-II methylprednisolone, 20 were enrolled between 2004 and 2006, 25 between 2007 and 2010, and one was enrolled between 2011 and March 2014. NASCIS-II methylprednisolone was initiated at least once at 7 of the 18 acute care RHSCIR sites, but 25 of the 46 patients who received NASCIS-II methylprednisolone did so at a non-RHSCIR community hospital prior to being transferred to a RHSCIR site. These patients received their NASCIS-II methylprednisolone prior to their baseline neurological examinations, which were performed upon arrival at the RHSCIR site.

\section{Baseline characteristics}

There were no significant baseline differences between the group of patients who received NASCIS-II methylprednisolone $(n=46)$ and the cohort of potential controls who received no steroid treatment $(n=1555)$ except that those who received NASCIS II methylprednisolone had a significantly longer time from injury to first ISNCSCI examination (median 72 vs. $56 \mathrm{~h}, p=0.01$; see Table 1 ).

\section{Propensity score matching}

Two of the 46 patients who received NASCIS-II methylprednisolone were excluded from the matched analysis because they had incomplete motor score outcome data. The remaining 44 were matched in a 1:1 ratio with controls who received no steroid treatment. The propensity score distributions within each group were similar (Fig. 2), and there were no significant differences in the proportions of patients with each combination of neurological level (cervical/thoracic) and ASIA Impairment Scale (A, B, C, or D), or any of the other baseline characteristics (Table 2). The median interval from injury to baseline neurological exam was $44 \mathrm{~h}$ (IQR 152) in the matched NASCIS-II methylprednisolone group and $31 \mathrm{~h}$ (IQR 170) in the matched no steroids group $(p=0.47)$, whereas the median interval from injury to final neurological exam was 127 days (IQR 142) in the matched NASCIS-II methylprednisolone group and 117 days (IQR 138) in the matched no steroids group $(p=0.78)$. Surgery was performed in $91 \%$ of the matched NASCIS-II methylprednisolone group and $82 \%$ of the matched no steroids group $(p=0.29)$.

\section{Motor score recovery}

There were no significant differences in motor recovery between the matched NASCIS-II methylprednisolone group and the matched no steroids group for each of TMS $(p=0.43)$, UEMS ( $p=0.38$ ), and LEMS ( $p=0.40$; see Fig. 3 ). Patients in the matched NASCIS-II methylprednisolone group experienced a mean TMS recovery of 13.7 points (SD 15.6), compared with 14.1 points (SD 21.6) for patients in the matched no steroids group. The mean UEMS recovery was 7.3 points (SD 8.4 ) in the matched NASCIS-II methylprednisolone group and 6.4 points (SD 12) in the matched no steroids group, and the mean LEMS recovery was 6.5 points (SD 10.7) in the matched NASCIS-II methylprednisolone group and 7.7 points (SD 12.5) in the matched no steroids group.
Table 1. Characteristics of Patients Who Received NASCIS-II METhylpREdNisolone or No Steroid TREATMENT

\begin{tabular}{lccc}
\hline Characteristic & $\begin{array}{c}\text { NASCIS-II } \\
\text { MPS }(\mathrm{n}=46)\end{array}$ & $\begin{array}{c}\text { No steroids } \\
(\mathrm{n}=1555)\end{array}$ & P value \\
\hline Age: mean (SD) & $45.9(16.6)$ & $45.0(18.6)$ & 0.82 \\
Male sex: $n(\%)$ & $38(82.6)$ & $1211(77.9)$ & 0.45 \\
$\begin{array}{l}\text { Injury to first neurological } \\
\text { exam, hours: median (IQR) }\end{array}$ & $72(154)$ & $56(172)$ & $0.01^{\mathrm{a}}$ \\
$\begin{array}{l}\text { Injury to final neurological } \\
\text { (1) }\end{array}$ & $142(96)$ & $124(100)$ & $0.17^{\mathrm{b}}$
\end{tabular}

exam, days: median (IQR)

ASIA Impairment Scale: $n$

A
B
C
D

D

Neurological level: $n$

Cervical

Thoracic

$\begin{array}{cc}21 & 536 \\ 6 & 152 \\ 8 & 264 \\ 11 & 384 \\ & \\ 32 & 796 \\ 14 & 458\end{array}$

0.82

152

264

796

0.39

Neurological level and ASIA Impairment Scale: $n$ Cervical

A
B
C

$\begin{array}{cc}12 & 260 \\ 4 & 87 \\ 6 & 173 \\ 10 & 253\end{array}$

Thoracic

A
B
C
D

High-energy: $n(\%)$

High

Low

Unknown

Treated with surgery: $n(\%)$

Yes

No

Unknown

Injury to time of surgery, h: median (IQR)

Glasgow Coma Scale: mean (SD)

Body Mass Index: mean (SD)

Injury Severity Score: mean (SD)

Charlson Comorbidity Index: mean (SD)

${ }^{\text {a}} \mathrm{P}$ value reported using categorical value.

${ }^{\mathrm{b}}$ Mann Whitney U test was used.

${ }^{\mathrm{c}}$ Patients treated without surgery were excluded.

ASIA, American Spinal Injury Association; IQR, interquartile range; MPS, methylprednisolone; NASCIS-II, Second National Spinal Cord Injury Study SD, standard deviation.

There was also no significant difference in motor recovery when we performed sensitivity analyses to compare the matched groups while adjusting for the matched variables using negative binomial regression (Table 3), or when we compared the NASCIS-II methylprednisolone group against the full cohort of unmatched potential controls $(n=1555)$ while adjusting for the same variables and RHSCIR site (Table 4). When analyzing cervical and thoracic injuries separately, the methylprednisolone group and the matched groups had near identical mean motor score recovery. Using the Mann-Whitney $U$ test to compare cervical patients treated with methylprednisolone versus matched patients and thoracic patients 
Unmatched NA SCIS-II MPS

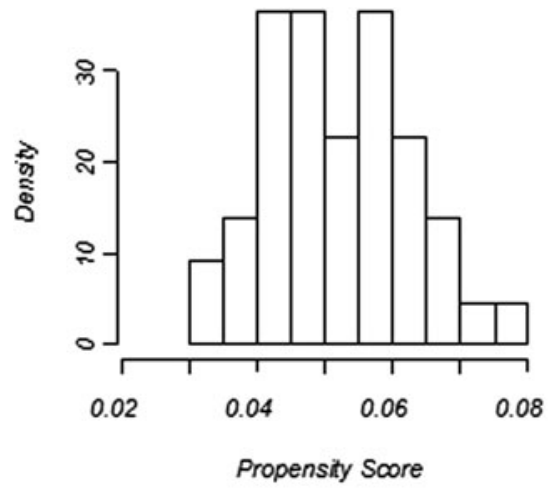

Unmatched no steroids

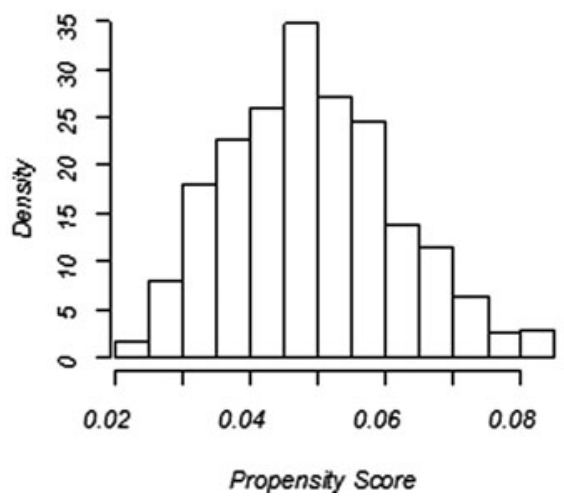

Matched NA SCIS-II MPS

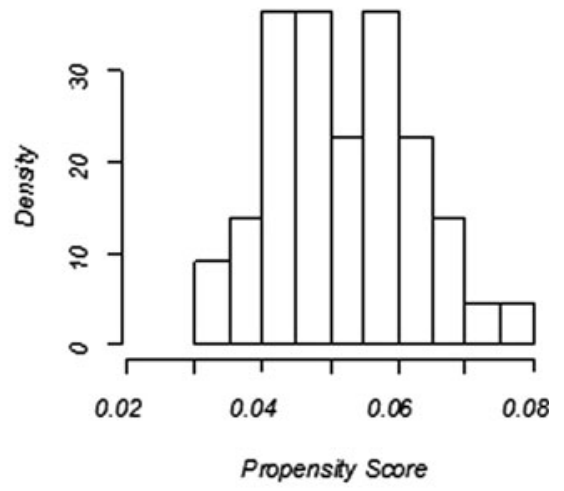

Matched no steroids

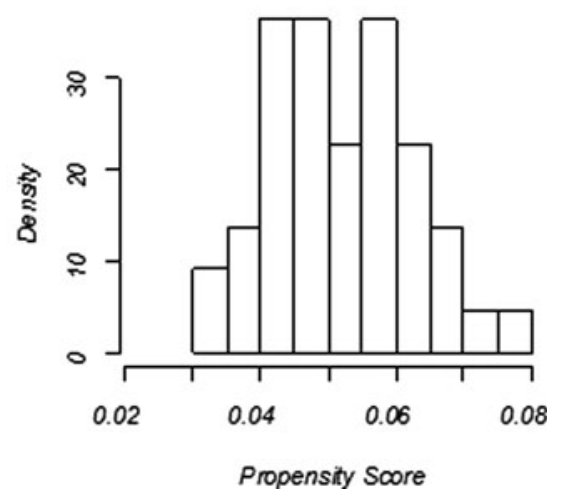

FIG. 2. Propensity histograms show the distributions of propensity scores among unmatched and matched patients who received NASCIS-II methylprednisolone or no steroids. MPS, methylprednisolone; NASCIS-II, Second National Spinal Cord Injury Study.

treated with methylprednisolone versus matched patients revealed no significant differences ( $p=0.65$ for cervical, $p=0.69$ for thoracic).

In the analysis of the full cohort of unmatched potential controls, cervical rather than thoracic injury levels $(p<0.01)$ and reduced baseline injury severity (ASIA Impairment Scale A, B, C, or D; $p<0.01)$ were each significantly associated with greater TMS recovery.

\section{Complications and length of stay}

The most common complications in either matched group were urinary tract infections, decubitus ulcers, and pneumonias. None of the patients in either group experienced in-hospital mortality and there were no surgical site infections. The NASCIS-II methylprednisolone group had a significantly higher rate of total complications ( $61 \%$ vs. $36 \% ; p=0.02)$, but there were not significant differences in the rates of specific complications between groups (Table 5).

Patients in the NASCIS-II methylprednisolone group experienced a significantly shorter mean length of stay in acute care (34.4 days vs. 48.4 days; $p=0.02)$, but there were no significant differences in the lengths of stay at inpatient rehabilitation (106.7 vs. 117.9 days; $p=0.45$ ) or the total lengths of stay, which is a combination of the acute care and inpatient rehabilitation lengths (mean 143.6 days vs. 152.9 days; $p=0.28$ ).

\section{Discussion}

Using data prospectively collected in the RHSCIR, we performed a propensity-matched cohort study and found that the
NASCIS-II regimen of methylprednisolone started within $8 \mathrm{~h}$ of injury did not improve motor recovery in comparison with no steroid treatment in patients with acute cervical and thoracic TSCIs. In a sensitivity analysis, cervical rather than thoracic injury level and reduced baseline injury severity were each associated with greater recovery. The NASCIS-II methylprednisolone group did not demonstrate a difference in motor recovery in cervical or thoracic patients when analyzed separately, but the methylprednisolone patients had a higher rate of total complications. There were no differences between groups for the rates of individual complications or for total length of stay.

\section{Strengths and limitations}

RHSCIR is part of the Translational Research Program of the Rick Hansen Institute, and it was created with the explicit purpose of facilitating clinical research to improve patient outcomes. Each data element was developed according to a priori research objectives and was standardized to optimize quality and accuracy ${ }^{32}$; ISNCSCI motor scores for this study were collected by trained clinical research staff and were verified using a customized electronic algorithm. ${ }^{42}$ Administration of the NASCIS-II bolus and infusion of methylprednisolone were confirmed to begin within $8 \mathrm{~h}$ of patients' injuries, as per this protocol.

The timing of ISNCSCI examinations was not standardized, and differences in timing could have introduced bias in the results. Early baseline examinations risk confounding due to spinal shock, and delayed baseline examinations risk missing early recovery. For 
Table 2. Propensity Score Matching of Patients Who ReCEIVED NASCIS-II METHYLPREDNISOLONE with Controls Who Received No Steroid Treatment

\begin{tabular}{|c|c|c|c|}
\hline Characteristic & $\begin{array}{c}N A S C I S-I I \\
M P S(\mathrm{n}=44)\end{array}$ & $\begin{array}{l}\text { No steroids } \\
\quad(\mathrm{n}=44)\end{array}$ & $\mathrm{P}$ value \\
\hline \multicolumn{4}{|l|}{ Matched variables } \\
\hline Age: mean (SD) & $45.4(16.2)$ & $45.5(16.6)$ & 0.97 \\
\hline Male sex: $n(\%)$ & $36(81.8)$ & $41(93.2)$ & 0.2 \\
\hline $\begin{array}{l}\text { Injury to first neurological } \\
\text { exam, hours: median (IQR) }\end{array}$ & $44(152)^{\mathrm{a}}$ & $31(170)$ & 0.47 \\
\hline \multicolumn{4}{|l|}{ ASIA Impairment Scale: $n$} \\
\hline A & 21 & 19 & 0.90 \\
\hline B & 6 & 5 & \\
\hline $\mathrm{C}$ & 7 & 7 & \\
\hline $\mathrm{D}$ & 10 & 13 & \\
\hline \multicolumn{4}{|l|}{ Neurological level: $n$} \\
\hline Cervical & 31 & 33 & 0.63 \\
\hline Thoracic & 13 & 11 & \\
\hline \multicolumn{4}{|l|}{ Neurological level and } \\
\hline \multicolumn{3}{|l|}{$\begin{array}{l}\text { ASIA Impairment Scale: } n \\
\text { Cervical }\end{array}$} & $000^{\mathrm{b}}$ \\
\hline $\begin{array}{l}\text { Cervical } \\
\text { A }\end{array}$ & 12 & 11 & $0.99^{\circ}$ \\
\hline $\mathrm{B}$ & 4 & 4 & \\
\hline $\mathrm{C}$ & 6 & 6 & \\
\hline $\mathrm{D}$ & 9 & 12 & \\
\hline \multicolumn{4}{|l|}{ Thoracic } \\
\hline A & 9 & 8 & \\
\hline B & 2 & 1 & \\
\hline $\mathrm{C}$ & 1 & 1 & \\
\hline $\mathrm{D}$ & 1 & 1 & \\
\hline \multicolumn{4}{|l|}{ Unmatched variables } \\
\hline \multicolumn{4}{|l|}{ High-energy: $n(\%)$} \\
\hline High & $19(43.2)$ & $20(45.5)$ & $0.51^{\mathrm{b}}$ \\
\hline Low & $25(56.8)$ & $22(50)$ & \\
\hline Unknown & 0 & $2(4.5)$ & \\
\hline \multicolumn{4}{|l|}{ Treated with surgery: $n(\%)$} \\
\hline Yes & $40(90.9)$ & $36(81.8)$ & $0.29^{\mathrm{b}}$ \\
\hline No & $4(9.1)$ & $6(13.6)$ & \\
\hline Unknown & 0 & $2(4.5)$ & \\
\hline $\begin{array}{l}\text { Injury to time of surgery, } \\
\text { h: median (IQR) }\end{array}$ & $33(41)$ & $33(26.25)$ & $0.96^{\mathrm{c}}$ \\
\hline $\begin{array}{l}\text { Glasgow Coma Scale: } \\
\text { mean (SD) }\end{array}$ & $14.4(1.7)$ & $14.3(2.7)$ & 0.84 \\
\hline Body Mass Index: mean (SD) & $26.9(7.2)$ & $26.7(5.7)$ & 0.86 \\
\hline $\begin{array}{l}\text { Injury Severity Score: } \\
\text { mean (SD) }\end{array}$ & $25.2(12.1)$ & $25.5(10.2)$ & 0.83 \\
\hline $\begin{array}{l}\text { Charlson Comorbidity Index: } \\
\text { mean (SD) }\end{array}$ & $0.19(0.46)$ & $0.3(0.79)$ & 0.93 \\
\hline $\begin{array}{l}\text { Injury to final neurological } \\
\text { exam, days: median (IQR) }\end{array}$ & $127(142)$ & 117 (138) & 0.78 \\
\hline
\end{tabular}

${ }^{\mathrm{a}}$ Three observations were excluded as outliers (time $>512 \mathrm{~h}$ ) for this variable only.

${ }^{\mathrm{b}} P$ values reported are based on Fisher's exact test by applying Monte Carlo estimation.

${ }^{\mathrm{c}}$ Patients treated without surgery were excluded.

ASIA, American Spinal Injury Association; IQR, interquartile range; MPS, methylprednisolone; SD, standard deviation.

example, the median time from injury to baseline examination was longer in the methylprednisolone group, and those patients who received methylprednisolone prior to their baseline examinations could have experienced some neurological recovery that was not captured. Nonetheless, Marino and colleagues showed that delays in baseline examinations are of minimal importance as long as they are conducted within 7 days. ${ }^{43}$ Neurological improvement may

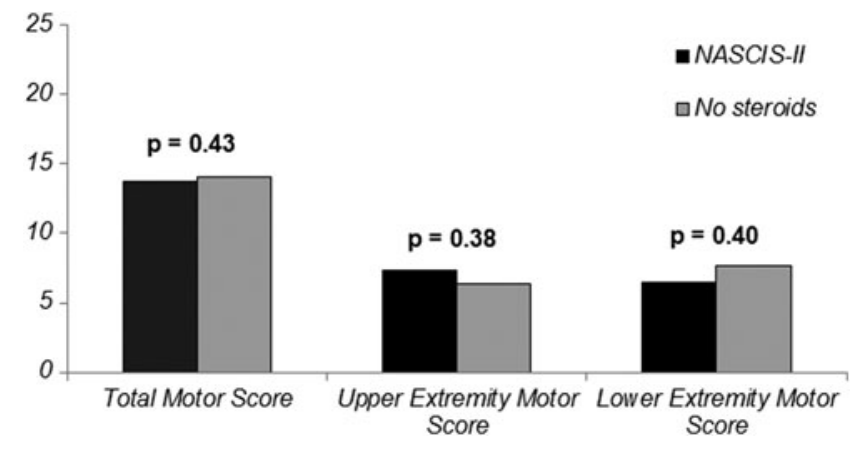

FIG. 3. Early motor recovery for patients who received NASCIS-II methylprednisolone(MPS; $n=44)$ compared with matched controls who received no steroids $(n=44) . P$ values are from Wilcoxon signed-ranks tests. NASCIS-II, Second National Spinal Cord Injury Study.

continue up to or beyond one year, ${ }^{44}$ but Pollard and Apple reported that more than $70 \%$ of neurological recovery occurs before discharge from rehabilitation. ${ }^{45}$

We identified only 46 patients who received the NASCIS-II regimen of methylprednisolone within $8 \mathrm{~h}$ of their injuries since 2005. This sample size is small and may limit confidence in our results, particularly the rates of complications. However, it is unlikely to reflect selection bias because RHSCIR includes all of the specialized acute care spine centers in Canada and methylprednisolone use is known to have sharply declined. ${ }^{21,23}$ For comparison, it is worthwhile to note that the analyses of the NASCIS II motor score improvements reported in a 2012 Cochrane Review rely on only 65 patients who received the NASCIS II protocol within $8 \mathrm{~h} .{ }^{15}$ Our finding that the frequency of NASCIS-II methylprednisolone administration has decreased over time suggests that the NASCIS-II protocol has fallen into widespread disfavor in Canada.

Table 3. Negative Binomial Regression Model of Total Motor Score Recovery on Age, Sex, Body Mass Index, ASIA Impairment Scale, and Level of InJury among Matched Patients Who Received NASCIS-II METHYLPREDNISOLONE $(N=44)$ or No Steroid Treatment $(N=44)$

\begin{tabular}{|c|c|c|c|c|}
\hline Variable & Coefficient & $\begin{array}{c}95 \% \\
C I: \\
\text { lower }\end{array}$ & $\begin{array}{c}95 \% \\
\text { CI: } \\
\text { upper }\end{array}$ & $\mathrm{P}$ value \\
\hline Age & -0.01 & -0.03 & -0.00 & 0.08 \\
\hline Male sex & -0.04 & -0.81 & 0.80 & 0.99 \\
\hline BMI & -0.04 & -0.08 & -0.01 & 0.11 \\
\hline ASIA Impairment Scale A & -1.59 & -2.31 & -0.87 & $<0.01$ \\
\hline ASIA Impairment Scale B & 0.69 & -0.10 & 1.48 & 0.09 \\
\hline ASIA Impairment Scale C & 1.17 & 0.46 & 1.88 & $<0.01$ \\
\hline ASIA Impairment Scale $\mathrm{D}^{\mathrm{a}}$ & - & - & - & - \\
\hline Cervical & 1.08 & 0.52 & 1.65 & $<0.01$ \\
\hline Thoracic $^{\mathrm{a}}$ & - & - & - & - \\
\hline NASCIS-II MPS & 0.04 & -0.44 & 0.52 & 0.87 \\
\hline No steroids ${ }^{\mathrm{a}}$ & - & - & - & - \\
\hline
\end{tabular}

${ }^{\mathrm{a}}$ Reference value.

AIS, American Spinal Injury Association; BMI, Body Mass Index; CI, confidence interval; MPS, methylprednisolone; NASCIS-II, Second National Spinal Cord Injury Study.

Bolded values were statistically significant. 
Table 4. Negative Binomial Regression Model of Total Motor Score Recovery on Age, Sex, ASIA Impairment

Scale, LeVel of InJury, and Site among Unmatched

Patients Who Received NASCIS-II Methylprednisolone $(N=44)$ Or No Steroid Treatment $(N=1555)$

\begin{tabular}{|c|c|c|c|c|}
\hline Variable & Coefficient & $\begin{array}{c}95 \% \\
\text { CI: } \\
\text { lower }\end{array}$ & $\begin{array}{c}95 \% \\
\text { CI: } \\
\text { upper }\end{array}$ & $\mathrm{P}$ value \\
\hline Age & 0.00 & 0.00 & 0.01 & 0.05 \\
\hline Male sex & 0.02 & -0.18 & -0.22 & 0.87 \\
\hline BMI & -0.00 & -0.01 & 0.01 & 0.77 \\
\hline ASIA Impairment Scale A & -0.45 & -0.68 & -0.22 & $<0.01$ \\
\hline ASIA Impairment Scale B & 0.82 & 0.56 & 1.08 & $<0.01$ \\
\hline ASIA Impairment Scale C & 1.13 & 0.96 & 1.3 & $<0.01$ \\
\hline ASIA Impairment Scale $D^{a}$ & - & - & - & - \\
\hline Cervical & 0.96 & 0.77 & 1.15 & $<0.01$ \\
\hline \multicolumn{5}{|l|}{ Thoracic $^{\mathrm{a}}$} \\
\hline NASCIS-II MPS & -0.13 & -0.43 & 0.16 & 0.38 \\
\hline No steroids ${ }^{\mathrm{a}}$ & - & - & - & - \\
\hline
\end{tabular}

${ }^{a}$ Reference value.

AIS, American Spinal Injury Association; BMI, Body Mass Index; CI confidence interval; MPS, methylprednisolone; NASCIS-II, Second National Spinal Cord Injury Study.

Bolded values were statistically significant.

We excluded 318 patients whose steroid administration status was indeterminate because many of these patients received various steroid preparations peri-operatively for off-label neuro-protective indications, and we chose not to impute missing data in order to avoid introducing extra variability. ${ }^{46} \mathrm{We}$ also excluded patients who received steroid regimens other than NASCIS-II methylprednisolone in order to minimize confounding. ${ }^{47}$

Propensity score matching is an analytical technique that pairs treated and untreated patients on the basis of their conditional probability of receiving an intervention according to a set of observed co-variates. ${ }^{37,38}$ Propensity score matching is more efficient than conventional multivariable regression when there are large differences in important prognostic characteristics between treatment groups, but its validity depends on the appropriate selection of covariates, matching techniques, and methods of final data analysis. ${ }^{39}$

Our propensity scores controlled for patients' neurological levels of injury and the baseline severity of their impairments, but our small sample precluded further differentiation according to high $(\mathrm{C} 1-\mathrm{C} 4)$

Table 5. Rates of In-hospital Complications for Patients Who Received NASCIS-II

MethylPREDNisolone COMPaRED With MatChed Controls Who Received No Steroids

\begin{tabular}{lccc}
\hline Outcome & $\begin{array}{c}\text { NASCIS-II } \\
\text { MPS }(\mathrm{n}=44)\end{array}$ & $\begin{array}{c}\text { No steroids } \\
(\mathrm{n}=44)\end{array}$ & $\mathrm{P}$ value \\
\hline Mortality & 0 & 0 & - \\
Urinary tract infection & 11 & 9 & 0.61 \\
Decubitus ulcer & 6 & 2 & 0.27 \\
Pneumonia & 7 & 4 & 0.52 \\
Deep vein thrombosis/ & 2 & 0 & 0.49 \\
$\quad$ pulmonary embolism & 0 & 0 & - \\
Surgical site infection & 1 & 1 & - \\
Sepsis & 27 & 16 & 0.02 \\
Total & & & \\
\hline
\end{tabular}

MPS, methylprednisolone; NASCIS-II, Second National Spinal Cord Injury Study. versus low (C5-T1) cervical injuries or thoracic (T2-T10) versus thoracolumbar (T11-L2)injuries. ${ }^{3}$ We were also unable to control for potential clustering due to local co-interventions at each RHSCIR site because more than half of the patients who received NASCIS-II methylprednisolone did so before arriving at a RHSCIR site. Propensity score matching cannot adjust for unknown confounders. ${ }^{48}$

Our approach to collecting complications data according to ICD10 codes from a national database is known to be at risk for underreporting, and ICD-10 codes may have been applied differently across the sites. Street and associates showed that nearly twice as many adverse events per person can be identified by prospectively applying the Spine Adverse Events Severity System. ${ }^{36}$ Our use of a composite endpoint for total complications was justified because the component endpoints are likely to be of similar importance to patients, occurred with similar frequency, and are likely to share similar underlying biological plausibility. ${ }^{49,50}$

The time from injury to first neurological examination was significantly longer in the group of patients who received NASCISII methylprednisolone in comparison with the larger cohort of potential controls who received no steroids, which may suggest that the patients who received NASCIS-II methylprednisolone had greater injury severity. However, we used propensity score matching and negative binomial regression to control for this potential confounder and the times from injury to first neurological examination were not significantly different between the matched group of patients who received no steroids. There were also no significant differences between the matched groups for Injury Severity Score, Glasgow Coma Scale, ASIA Impairment Scale, or neurological level of injury.

We prospectively verified whether the patients who received NASCIS II methylprednisolone did so within $8 \mathrm{~h}$ of their injuries, but it is possible that the effect of NASCIS-II methylprednisolone might further vary according to whether patients received it earlier or later within $8 \mathrm{~h}$ of their injuries. In NASCIS-III, the 24-h regimen of methylprednisolone begun within the first $3 \mathrm{~h}$ after injury was not as effective if its initiation was delayed until between 3 and $8 \mathrm{~h}^{26}$ Our study was not designed to investigate this issue, however, and we did not collect exact timing data to explore it.

Surgical timing may be an important modifiable determinant of the outcomes in the management of patients with TSCIs. Decompression prior to $24 \mathrm{~h}$ was associated with improved neurological outcomes among RHSCIR patients with ASIA B, C, or D cervical, thoracic, or thoracolumbar injuries, ${ }^{31}$ and it was also associated with improved outcomes in the Surgical Timing in Acute Spinal Cord Injury Study (STASCIS). ${ }^{51}$ A multivariate analysis of the STASCIS data suggested that methylprednisolone could have a synergistic effect with early decompression, and the incidence of wound infections among patients who received NASCIS-II methylprednisolone was lower in STASCIS than in the NASCIS-II trial. ${ }^{52}$ However, STASCIS included only patients with cervical SCIs, who were more likely to undergo anterior surgery rather than posterior surgery, which may explain the reduced infection rates. ${ }^{20}$ It is unlikely that surgical timing was a confounder in our study because the difference in the timing of surgery between the matched groups was not significant.

\section{Relation to previous literature}

Our results support a considerable body of literature that fails to demonstrate a benefit attributable to methylprednisolone for neurological functional recovery in patients with acute TSCIs, and our study is the first to adjust for patients' neurological level of injury 
and the baseline severity of their impairments. ${ }^{16,28,53,54}$ The original NASCIS-I trial found no significant differences in motor recovery at 6 months among 330 patients who were randomized to high- versus low-dose 10-day regimens of methylprednisolone, ${ }^{55}$ the primary analysis of NASCIS-II found no significant differences in motor recovery at 6 months among 487 patients who were randomized to a 24-h regimen of methylprednisolone versus either naloxone or placebo, ${ }^{13}$ and the primary analysis of NASCIS-III found no significant differences in motor recovery at 6 months among 499 patients who were randomized to $24 \mathrm{~h}$ or methylprednisolone, $48 \mathrm{~h}$ of methylprednisolone, or tirilazad. ${ }^{26}$ A secondary analysis of 65 NASCIS-II patients who received methylprednisolone within $8 \mathrm{~h}$ of injury found that this subgroup experienced significantly improved sensory and motor recovery at 6 months. ${ }^{13}$

More recently, Chikuda and colleagues compared methylprednisolone against no steroid treatment in a propensity-matched analysis of their nationwide administrative database in Japan. ${ }^{56}$ They matched 824 pairs of patients with cervical SCIs and found significantly higher rates of major complications including respiratory complications, urinary tract infections, sepsis, gastrointestinal bleedings, and pulmonary emboli in patients who received high doses of methylprednisolone, as well as longer lengths of stay. Their study did not specify whether lengths of stay included inpatient rehabilitation, did not include motor scores, did not control for levels or injury or severity of impairment, and did not verify that all patients received the NASCIS-II regimen within $8 \mathrm{~h}$ of their injuries. Three other small randomized trials and several earlier observational studies have been previously reviewed. ${ }^{16,28,53,54}$

\section{Implications}

Evidence-based medicine describes the careful integration of patient preferences and clinician expertise with the best available external evidence to facilitate decision-making, and clinicians, researchers, and other evidence users should consider the totality of relevant evidence before applying results to patient care. ${ }^{57}$ Metaanalyses are systematic reviews in which the results from similar studies are combined using statistical tests to produce pooled treatment effects, and they are powerful tools that can synthesize conflicting literature and evaluate bias. However, they require high methodological credibility in order to avoid misleading conclusions. ${ }^{58}$

Bracken and Botelho and colleagues have each reported on meta-analyses that evaluate the effect of methylprednisolone against placebo in patients with TSCIs, but the conclusions from these studies are conflicting and each is limited by poor methodological credibility. ${ }^{15,59}$ Neither ensured that the selection of studies was reproducible, neither explored possible explanations for between-studies differences in results, and neither study addressed the overall quality of the evidence or confidence in the pooled estimates. ${ }^{58}$ According to the Grades of Recommendation, Assessment, Development and Evaluation (GRADE) approach, confidence in pooled effect estimates depends on study design, risk of bias, imprecision, inconsistency, indirectness, publication bias, and other factors. ${ }^{60}$ An updated independent meta-analysis could help resolve any ongoing controversy, and the open release of individual participant data for this purpose would allow adjustments for the prognostic importance of patients' neurological levels of injury and the baseline severity of their impairments. ${ }^{61-63}$

The clinical validation of novel interventions to treat patients with acute TSCIs remains an urgent ongoing research priority. ${ }^{64,65}$ Randomized controlled trials are the most rigorous clinical research studies for investigating treatment effects and establishing causal- ity, but their design and conduct for interventions in patients with acute TSCIs is challenging. The number of patients who might be eligible for enrollment at individual institutions is surprisingly small, and complex stratification is required to account for variability in baseline prognostic factors. ${ }^{3,10}$ Multi-center trials can achieve sufficient power, but they require extensive coordination, collaboration, and resources. ${ }^{66}$ Large observational studies can overcome some of these challenges, but they must be also appropriately designed and implemented in order to minimize bias. ${ }^{48}$

The Joint Section on Spine and Peripheral Nerves of the American Association of Neurological Surgeons and Congress of Neurological Surgeons recommended against the routine administration of methylprednisolone for the treatment of acute TSCIs in $2013 .^{28}$ Their guidelines highlight that methylprednisolone is not approved by the Food and Drug Administration for use in TSCIs, there is no Class I or Class II medical evidence supporting clinical benefit, and there is Class I, II, and III evidence suggesting harmful side effects including death. The Canadian Neurosurgical Society, the Canadian Spine Society, and the Canadian Association of Emergency Physicians have previously contributed to position statements recognizing insufficient evidence to support the use of high-dose methylprednisolone in acute TSCIs. ${ }^{21,29}$

\section{Conclusions}

NASCIS-II methylprednisolone started within $8 \mathrm{~h}$ of injury did not improve motor score recovery in RHSCIR patients with acute cervical or thoracic TSCIs. These findings support guideline recommendations against its routine administration, and validate trends toward decreasing utilization. Clinicians, researchers, and other evidence users should consider these results in the context of a considerable body of evidence, and should recognize that patients' neurological levels of injury and the baseline severity of their impairments are important prognostic factors that warrant further consideration.

\section{Acknowledgments}

The authors would like to thank the RHSCIR network and all the participating local RHSCIR sites: GF Strong Rehabilitation Centre, Vancouver General Hospital, Foothills Hospital, Glenrose Rehabilitation Hospital, Royal Alexandra Hospital, University of Alberta Hospital, Royal University Hospital, Saskatoon City Hospital, Winnipeg Health Sciences Centre, Toronto Western Hospital, Toronto Rehabilitation Institute, St. Michael's Hospital, Sunnybrook Health Sciences Centre, Hamilton General Hospital, Hamilton Health Sciences Regional Rehabilitation Centre, Victoria Hospital (London), University Hospital (London), Parkwood Hospital (London), The Ottawa Hospital Rehabilitation Centre, The Ottawa Hospital Civic Campus, Hopital de l'Enfant Jesus, Institut de readaptation en deficience physique de Quebec, Centre de readaptation Lucie-Bruneau, Institut de readaptation Gingras-Lindsay-deMontreal, Hopital du SacreCœur de Montreal, Nova Scotia Rehabilitation Centre, QEII Health Sciences Centre, Saint John Regional Hospital, Stan Cassidy Centre for Rehabilitation, St. John's Health Sciences Centre, and L.A. Miller Rehabilitation Centre.

The Rick Hansen Spinal Cord Injury Registry and this work are supported by funding from the Rick Hansen Institute, Health Canada, Western Economic Diversification Canada, and the Governments of Alberta, British Columbia, Manitoba, and Ontario.

\section{Author Disclosure Statement}

No competing financial interests exist. 


\section{References}

1. WHO. Spinal Cord Injury, Fact Sheet. Available at 2013.http:// www.who.int/mediacentre/factsheets/fs $384 / \mathrm{en} /$. Accessed

2. Singh, A., Tetreault, L., Kalsi-Ryan, S., Nouri, A., Fehlings, M.G. (2014). Global prevalence and incidence of traumatic spinal cord injury. Clin. Epidemiol. 6, 309-331.

3. Dvorak, M.F., Noonan, V.K., Fallah, N., Fisher, C.G., Rivers, C.S., Ahn, H., Tsai, E.C., Linassi, A.G., Christie, S.D., Attabib, N., Hurlbert, R.J., Fourney, D.R., Johnson, M.G., Fehlings, M.G., Drew, B., Bailey, C.S., Paquet, J., Parent, S., Townson, A., Ho, C., Craven, B.C., Gagnon, D., Tsui, D., Fox, R., Mac-Thiong, J.M., Kwon, B. (2014). Minimizing errors in acute traumatic spinal cord injury trials by acknowledging the heterogeneity of spinal cord anatomy and injury severity: an observational Canadian cohort analysis. J. Neurotrauma $31,1540-1547$

4. Noonan, V.K., Fallah, N., Park, S.E., Dumont, F.S., Leblond, J., Cobb J., Noreau, L. (2014). Health care utilization in persons with traumatic spinal cord injury: the importance of multimorbidity and the impact on patient outcomes. Top Spinal Cord Inj. Rehabil. 20, 289-301.

5. DeVivo, M.J. (1997). Causes and costs of spinal cord injury in the United States. Spinal Cord 35, 809-813.

6. Krueger, H., Noonan, V.K., Trenaman, L.M., Joshi, P., Rivers, C.S (2013). The economic burden of traumatic spinal cord injury in Canada. Chronic Inj. Can. 33, 113-122.

7. Noonan, V.K., Fingas, M., Farry, A., Baxter, D., Singh, A., Fehlings, M.G., Dvorak, M.F. (2012). Incidence and prevalence of spinal cord injury in Canada: a national perspective. Neuroepidemiology 38, 219-226.

8. Selvarajah, S., Hammond, E.R., Haider, A.H., Abularrage, C.J., Becker, D., Dhiman, N., Hyder, O., Gupta, D., Black, J.H. 3rd, Schneider E.B. (2014). The burden of acute traumatic spinal cord injury among adults in the United States: an update. J. Neurotrauma $31,228-238$.

9. Wyndaele, M., Wyndaele, J.J. (2006). Incidence, prevalence and epidemiology of spinal cord injury: what learns a worldwide literature survey? Spinal Cord 44, 523-529.

10. Lee, R.S., Noonan, V.K., Batke, J., Ghag, A., Paquette, S.J., Boyd, M.C., Fisher, C.G., Street, J., Dvorak, M.F., Kwon, B.K. (2012). Feasibility of patient recruitment into clinical trials of experimental treatments for acute spinal cord injury. J. Clin. Neurosci 19, 1338-1343.

11. Kwon, B.K., Tetzlaff, W., Grauer, J.N., Beiner, J., Vaccaro, A.R. (2004). Pathophysiology and pharmacologic treatment of acute spinal cord injury. Spine J. 4, 451-464.

12. Lenzer, J. (2013). Why we can't trust clinical guidelines. BMJ. 346 , f3830.

13. Bracken, M.B., Shepard, M.J., Collins, W.F., Holford, T.R., Young, W., Baskin, D.S., Eisenberg, H.M., Flamm, E., Leo-Summers, L., Maroon, J., Marshall, L.F., Perot, P.L. Jr., Piepmeier, J., Sonntag, V.K.H., Wagner, F.C., Wilberger, J.E., Winn, H.R. (1990). A randomized, controlled trial of methylprednisolone or naloxone in the treatment of acute spinal-cord injury. Results of the Second National Acute Spinal Cord Injury Study. N. Engl. J. Med. 322, $1405-1411$.

14. Coleman, W.P., Benzel, D., Cahill, D.W., Ducker, T., Geisler, F., Green, B., Gropper, M.R., Goffin, J., Madsen, P.W. 3rd, Maiman, D.J., Ondra, S.L., Rosner, M., Sasso, R.C., Trost, G.R., Zeidman, S. (2000). A critical appraisal of the reporting of the National Acute Spinal Cord Injury Studies (II and III) of methylprednisolone in acute spinal cord injury. J. Spinal Disord. 13, 185-199.

15. Bracken, M.B. (2012). Steroids for acute spinal cord injury. Cochrane Database Syst. Rev. 1, Cd001046.

16. Hurlbert, R.J. (2000). Methylprednisolone for acute spinal cord injury: an inappropriate standard of care. J. Neurosurg. 93, 1-7.

17. Hurlbert, R.J. (2014). Methylprednisolone for the treatment of acute spinal cord injury: point. Neurosurgery 61 Suppl 1, 32-35.

18. Akl, E.A., Briel, M., You, J.J., Sun, X., Johnston, B.C., Busse, J.W., Mulla, S., Lamontagne, F., Bassler, D., Vera, C., Alshurafa, M., Katsios, C.M., Zhou, Q., Cukierman-Yaffe, T., Gangii, A., Mills, E.J., Walter, S.D., Cook, D.J., Schünemann, H.J., Altman, D.G., Guyatt, G.H. (2012). Potential impact on estimated treatment effects of information lost to follow-up in randomised controlled trials (LOST-IT): systematic review. BMJ. 344, e2809.

19. Sun, X., Briel, M., Busse, J.W., You, J.J., Akl, E.A., Mejza, F., Bala, M.M., Bassler, D., Mertz, D., Diaz-Granados, N., Vandvik, P.O., Malaga, G., Srinathan, S.K., Dahm, P., Johnston, B.C., Alonso-Coello, P.,
Hassouneh, B., Walter, S.D., Heels-Ansdell, D., Bhatnagar, N., Altman, D.G., Guyatt, G.H. (2012). Credibility of claims of subgroup effects in randomised controlled trials: systematic review. BMJ. 344, e1553.

20. Fehlings, M.G., Wilson, J.R., Cho, N. (2014). Methylprednisolone for the treatment of acute spinal cord injury: counterpoint. Neurosurgery 61 Suppl 1, 36-42.

21. Hurlbert, R.J., Moulton, R. (2002). Why do you prescribe methylprednisolone for acute spinal cord injury? A Canadian perspective and a position statement. Can. J. Neurol. Sci. 29, 236-239.

22. Schroeder, G.D., Kwon, B.K., Eck, J.C., Savage, J.W., Hsu, W.K., Patel, A.A. (2014). Survey of cervical spine research society members on the use of high-dose steroids for acute spinal cord injuries. Spine (Phila. Pa. 1976) 39, 971-977.

23. Hurlbert, R.J., Hamilton, M.G. (2008). Methylprednisolone for acute spinal cord injury: 5-year practice reversal. Can. J. Neurol. Sci. 35, 41-45.

24. Miekisiak, G., Kloc, W., Janusz, W., Kaczmarczyk, J., Latka, D., Zarzycki, D. (2014). Current use of methylprednisolone for acute spinal cord injury in Poland: survey study. Eur. J. Orthop. Surg. Traumatol. 24, Suppl 1, S269-S273.

25. Druschel, C., Schaser, K.D., Schwab, J.M. (2013). Current practice of methylprednisolone administration for acute spinal cord injury in Germany: a national survey. Spine (Phila. Pa. 1976) 38, E669-E677.

26. Bracken, M.B., Shepard, M.J., Holford, T.R., Leo-Summers, L., Aldrich, E.F., Fazl, M., Fehlings, M., Herr, D.L., Hitchon, P.W., Marshall, L.F., Nockels, R.P., Pascale, V., Perot, P.L. Jr., Piepmeier, J., Sonntag, V.K., Wagner, F., Wilberger, J.E., Winn, H.R., Young, W. (1997). Administration of methylprednisolone for 24 or 48 hours or tirilazad mesylate for 48 hours in the treatment of acute spinal cord injury. Results of the Third National Acute Spinal Cord Injury Randomized Controlled Trial. National Acute Spinal Cord Injury Study. JAMA. 277, 1597-1604.

27. Edwards, P., Arango, M., Balica, L., Cottingham, R., El-Sayed, H., Farrell, B., Fernandes, J., Gogichaisvili, T., Golden, N., Hartzenberg, B., Husain, M., Ulloa, M.I., Jerbi, Z., Khamis, H., Komolafe, E. Laloë, V., Lomas, G., Ludwig, S., Mazairac, G., Muñoz Sanchéz, Mde L., Nasi, L., Olldashi, F., Plunkett, P., Roberts, I., Sandercock, P., Shakur, H., Soler, C., Stocker, R., Svoboda, P., Trenkler, S., Venkataramana, N.K., Wasserberg, J., Yates, D., Yutthakasemsunt, S., CRASH trial collaborators. (2005). Final results of MRC CRASH, a randomised placebo-controlled trial of intravenous corticosteroid in adults with head injury-outcomes at 6 months. Lancet 365, 19571959

28. Walters, B.C., Hadley, M.N., Hurlbert,R.J., Aarabi, B., Dhall, S.S. Gelb, D.E., Harrigan, M.R., Rozelle, C.J., Ryken, T.C., Theodore, N.; American Association of Neurological Surgeons; Congress of Neurological Surgeons. (2013). Guidelines for the management of acute cervical spine and spinal cord injuries: 2013 update. Neurosurgery 60 , Suppl 1, 82-91.

29. Hugenholtz, H., Cass, D.E., Dvorak, M.F., Fewer, D.H., Fox, R.J., Izukawa, D.M., Lexchin, J., Tuli, S., Bharatwal, N., Short, C. (2002). High-dose methylprednisolone for acute closed spinal cord injuryonly a treatment option. Can. J. Neurol. Sci. 29, 227-235.

30. Pharmacological therapy after acute cervical spinal cord injury. (2002). Neurosurgery 50, Suppl. 3, S63-S72.

31. Dvorak, M.F., Noonan, V.K., Fallah, N., Fisher, C.G., Finkelstein, J., Kwon, B.K., Rivers, C.S., Ahn, H., Paquet, J., Tsai, E.C., Townson, A., Attabib, N., Bailey, C.S., Christie, S.D., Drew, B., Fourney, D.R., Fox, R., Hurlbert, R.J., Johnson, M.G., Linassi, A.G., Parent, S., Fehlings, M.G. (2015). The influence of time from injury to surgery on motor recovery and length of hospital stay in acute traumatic spinal cord injury: an observational Canadian cohort study. J. Neurotrauma $32,654-654$

32. Noonan, V.K., Kwon, B.K., Soril, L., Fehlings, M.G., Hurlbert, R.J., Townson, A., Johnson, M., Dvorak, M.F.; RHSCIR Network.(2012). The Rick Hansen Spinal Cord Injury Registry (RHSCIR): a national patient-registry. Spinal Cord 50, 22-27.

33. Noonan, V.K., Thorogood, N.P., Joshi, P.B., Fehlings, M.G., Craven, B.C., Linassi, G., Fourney, D.R., Kwon, B.K., Bailey, C.S., Tsai, E.C., Drew, B.M., Ahn, H., Tsui, D., Dvorak, M.F. (2013). Meeting the privacy requirements for the development of a multi-centre patient registry in Canada: the Rick Hansen Spinal Cord Injury Registry. Healthc. Policy 8, 87-99.

34. Kirshblum, S., Waring, W. (2014). Updates for the International Standards for Neurological Classification of Spinal Cord Injury. Phys. Med. Rehabil. Clin. N. Am. 25, 505-517, vii. 
35. Charlson, M.E., Pompei, P., Ales, K.L., MacKenzie, C.R. (1987). A new method of classifying prognostic comorbidity in longitudinal studies: development and validation. J. Chronic. Dis. 40, 373-383.

36. Street, J.T., Thorogood, N.P., Cheung, A., Noonan, V.K., Chen, J., Fisher, C.G., Dvorak, M.F. (2013). Use of the Spine Adverse Events Severity System (SAVES) in patients with traumatic spinal cord injury. A comparison with institutional ICD-10 coding for the identification of acute care adverse events. Spinal Cord 51, 472-476.

37. Biondi-Zoccai, G., Romagnoli, E., Agostoni, P., Capodanno, D., Castagno, D., D’Ascenzo, F., Sangiorgi, G., Modena, M.G. (2011). Are propensity scores really superior to standard multivariable analysis? Contemp. Clin. Trials 32, 731-740.

38. Garrido, M.M., Kelley, A.S., Paris, J., Roza, K., Meier, D.E., Morrison, R.S., Aldridge, M.D. (2014). Methods for constructing and assessing propensity scores. Health Serv. Res. 49, 1701-1720.

39. Streiner, D.L., Norman, G.R. (2012). The pros and cons of propensity scores. Chest 142, 1380-1382.

40. Thabane, L., Mbuagbaw, L., Zhang, S., Samaan, Z., Marcucci, M., Ye, C., Thabane, M., Giangregorio, L., Dennis, B., Kosa, D., Borg Debono, V., Dillenburg, R., Fruci, V., Bawor. M., Lee, J., Wells, G., Goldsmith, C.H. (2013). A tutorial on sensitivity analyses in clinical trials: the what, why, when and how. BMC. Med. Res. Methodol. $13,92$.

41. Scharfstein, D.O., Hogan, J., Herman, A. (2012). On the prevention and analysis of missing data in randomized clinical trials: the state of the art. J. Bone Jt. Surg. Am. 94, Suppl 1, 80-84.

42. Schuld, C., Wiese, J., Franz, S., Putz, C., Stierle, I., Smoor, I.,Weidner, N.; EMSCI Study Group, Rupp, R. (2013). Effect of formal training in scaling, scoring and classification of the International Standards for Neurological Classification of Spinal Cord Injury. Spinal Cord 51, 282-288.

43. Marino, R.J., Burns, S., Graves, D.E., Leiby, B.E., Kirshblum, S., Lammertse, D.P. (2011). Upper- and lower-extremity motor recovery after traumatic cervical spinal cord injury: an update from the national spinal cord injury database. Arch. Phys. Med. Rehabil. 92, 369-375.

44. Kirshblum, S., Millis, S., McKinley, W., Tulsky, D. (2004). Late neurologic recovery after traumatic spinal cord injury. Arch. Phys. Med. Rehabil. 85, 1811-1817.

45. Pollard, M.E., Apple, D.F. (2003). Factors associated with improved neurologic outcomes in patients with incomplete tetraplegia. Spine (Phila. Pa. 1976) 28, 33-39.

46. Groenwold, R.H., Donders, A.R., Roes, K.C., Harrell, F.E., Moons, K.G. (2012). Dealing with missing outcome data in randomized trials and observational studies. Am. J. Epidemiol. 175, 210-217.

47. Kiwerski, J.E. (1993). Application of dexamethasone in the treatment of acute spinal cord injury. Injury 24, 457-460.

48. Hoppe, D.J., Schemitsch, E.H., Morshed, S., Tornetta, P., Bhandari, M. (2009). Hierarchy of evidence: where observational studies fit in and why we need them. J. Bone Jt. Surg. Am. 91, Suppl 3, 2-9.

49. Montori, V.M., Permanyer-Miralda, G., Ferreira-González, I., Busse, J.W., Pacheco-Huergo, V., Bryant, D., Alonso, J., Akl, E.A., DomingoSalvany, A., Mills, E., Wu, P., Schünemann, H.J., Jaeschke, R., Guyatt, G.H. (2005). Validity of composite end points in clinical trials. BMJ. 330, 594-596.

50. Busse, J.W., Bhandari, M., Ferreira-González, I., Montori, V.M., Guyatt, G.H.(2012). Use andinterpretation of composite end points in orthopaedic trials. J. Bone Jt. Surg. Am. 94, Suppl 1, 65-69.

51. Fehlings, M.G., Vaccaro, A., Wilson, J.R., Singh, A., Cadotte, D., Harrop, J.S., Aarabi, B., Shaffrey, C., Dvorak, M,. Fisher, C., Arnold, P., Massicotte, E.M., Lewis, S., Rampersaud, R. (2012). Early versus delayed decompression for traumatic cervical spinal cord injury: results of the Surgical Timing in Acute Spinal Cord Injury Study (STASCIS). PLoS. One 7, e32037.

52. Wilson, J.R., Arnold, P.M., Singh, A., Kalsi-Ryan, S., Fehlings, M.G. (2012). Clinical prediction model for acute inpatient complications after traumatic cervical spinal cordinjury: a subanalysis from the Surgical Timing in Acute Spinal Cord Injury Study. J. Neurosurg. Spine 17, Suppl 1, 46-51.
53. Hurlbert, R.J., Hadley, M.N., Walters, B.C., Aarabi, B., Dhall, S.S., Gelb, D.E., Rozzelle, C.J., Ryken, T.C., Theodore, N. (2013). Pharmacological therapy for acute spinal cord injury. Neurosurgery 72 , Suppl 2, 93-105.

54. Hurlbert, R.J. (2001). The role of steroids in acute spinal cord injury: an evidence-based analysis. Spine (Phila. Pa. 1976) 26, S39-S46.

55. Bracken, M.B., Collins, W.F., Freeman, D.F., Shepard, M.J., Wagner, F.W., Silten, R.M., Hellenbrand, K.G., Ransohoff, J., Hunt, W.E., Perot, P.L. Jr., Grossman, R.G., Green, B.A., Eisenberg, H.M., Rifkinson, N., Goodman, J.H., Meagher, J.N., Fischer, B., Clifton, G.L., Flamm, E.S., Rawe, S.E. (1984). Efficacy of methylprednisolone in acute spinal cord injury. JAMA. 251, 45-52.

56. Chikuda, H., Yasunaga, H., Takeshita, K., Horiguchi, H., Kawaguchi, H., Ohe, K., Fushimi, K., Tanaka, S. (2014). Mortality and morbidity after high-dose methylprednisolone treatment in patients with acute cervical spinal cord injury: a propensity-matched analysis using a nationwide administrative database. Emerg. Med. J. 31, 201-206.

57. Fisher, C.G., Wood, K.B. (2007). Introduction to and techniques of evidence-based medicine. Spine (Phila. Pa. 1976) 32, S66-S72.

58. Murad, M.H., Montori, V.M., Ioannidis, J.P., Jaeschke, R., Devereaux, P.J., Prasad, K., Neumann, I., Carrasco-Labra, A., Agoritsas, T., Hatala, R., Meade, M.O., Wyer, P., Cook, D.J., Guyatt, G. (2014). How to read a systematic review and meta-analysis and apply the results to patient care: users' guides to the medical literature. JAMA. 312, 171-179.

59. Botelho, R.V., Daniel, J.W., Boulosa, J.L., Colli, B.O., Farias, Rde. L, Moraes, O.J., Pimenta, W.E. Jr, Ribeiro, C.H., Ribeiro, F.R., Taricco, M.A., Carvalho, M.V., Bernardo, W.M. (2009). Effectiveness of methylprednisolone in the acute phase of spinal cord injuries-a systematic review of randomized controlled trials. Rev. Assoc. Med. Bras. 55, 729-737.

60. Balshem, H., Helfand, M., Schunemann, H.J., Oxman, A.D., Kunz, R., Brozek, J., Vist, G.E., Falck-Ytter, Y., Meerpohl, J., Norris, S., Guyatt, G.H. (2011). GRADE guidelines: 3. Rating the quality of evidence. J. Clin. Epidemiol. 64, 401-406.

61. Simmonds, M.C., Brown, J.V., Heirs, M.K., Higgins, J.P., Mannion, R.J., Rodgers, M.A., Stewart, L.A. (2013). Safety and effectiveness of recombinant human bone morphogenetic protein-2 for spinal fusion: a meta-analysis of individual-participant data. Ann. Intern. Med. 158, 877-889.

62. Fu, R., Selph, S., McDonagh,M., Peterson, K.,Tiwari, A., Chou, R., Helfand, M. (2013). Effectiveness and harms of recombinant human bone morphogenetic protein-2 in spine fusion: a systematic review and meta-analysis. Ann. Intern. Med. 158, 890-902.

63. Krumholz, H.M., Ross, J.S., Gross, C.P., Emanuel, E.J., Hodshon, B., Ritchie, J.D., Low, J.B., Lehman, R. (2013). A historic moment for open science: the Yale University Open Data Access project and medtronic. Ann. Intern. Med. 158, 910-911.

64. Kwon, B.K., Casha, S., Hurlbert, R.J., Yong, V.W. (2011). Inflammatory and structural biomarkers in acute traumatic spinal cord injury. Clin. Chem. Lab. Med. 49, 425-433.

65. Casha, S., Zygun, D., McGowan, M.D., Bains, I., Yong, V.W., Hurlbert, R.J. (2012). Results of a phase II placebo-controlled randomized trial of minocycline in acute spinal cord injury. Brain 135, 1224-1236.

66. Slobogean, G.P., Sprague, S., Bhandari, M. (2012). The tactics of large randomized trials. J. Bone Jt. Surg. Am. 94, Suppl 1, 19-23.

Address correspondence to: Marcel F. Dvorak, MD

Blusson Spinal Cord Centre 818 West 10th Avenue Vancouver, British Columbia V5Z 1 M9 Canada

E-mail: Marcel.Dvorak@ubc.ca 